\title{
Solar Home Systems: A comprehensive literature review for Sub- Saharan Africa
}

\author{
Vivien Kizilcec ${ }^{\mathrm{a}}$ \\ $\mathrm{a}=$ Engineering for International Development Research Centre, Civil, Environmental and \\ Geomatic Engineering, University College London, WC1E 6BT, London, United Kingdom \\ Priti Parikh ${ }^{\mathrm{b}, *}$ \\ $\mathrm{b}=$ Engineering for International Development Research Centre, Civil, Environmental and \\ Geomatic Engineering, University College London, WC1E 6BT, London, United Kingdom
}

*Corresponding Author, priti.parikh@ucl.ac.uk

\begin{abstract}
$\underline{\text { Abstract }}$
Solar home systems (SHSs) have seen rapid growth and have proven to be a viable source of electricity for households due to their capability to reach remote users that do not have access to grid systems. Based on a comprehensive literature review of 139 papers focussing on SHSs in Sub-Saharan Africa, this paper highlights the key trends, research gaps and policy recommendations. The literature was categorised into four themes: institutional, technology, viability and user-centric. The review finds that the current primary themes of research are technology, user-centric and viability. This highlights the need for further research into the institutional barriers, need for a regulatory framework and stronger incentives for scale-up of SHSs. PAYG systems are gaining ground in off-grid solar markets providing flexibility on payments for consumers in resource challenged settings. The authors also identified paucity of research in countries with low electrification rates, highlighting new locations for SHS research.
\end{abstract}

Keywords: Solar home systems; SHS; Off-grid energy; Energy access; Sub-Saharan Africa; Literature review 


\section{Introduction}

\subsection{Aim}

Solar home systems (SHSs) have seen rapid adoption due to their ability to power households who lack access to a reliable grid connection (Levin \& Thomas, 2016). There is potential for future growth, as $80 \%$ of the population currently living without electricity are located in remote communities, which are often more onerous for grid extension, due to low user density and challenging terrain (IEA, 2017).

The aim of this paper was to conduct a comprehensive literature review on SHSs in Sub-Saharan Africa (SSA), under the four themes of institutional, technology, viability and user-centric, building on the work of Schillebeeckx et al. (2012). The novelty of this paper is the utilisation of these themes to investigate a wide range of publications that exclusively focus on SHSs in SSA. Through a review of 139 papers across three databases, we highlight key topics of interest in the field, as well as provide recommendations for both policy and future research. These findings can assist a diverse range of stakeholders, such as policy makers, academics and practitioners to provide access to affordable and sustainable energy thereby supporting the ambitions of the Energy Sustainable Development Goal (SDG7).

\subsection{Energy access and the off-grid market}

Globally, the number of people that lack access to electricity has fallen from 1.7 billion in 2000 to 850 million in 2018 (IEA, 2018, 2019c). However, most of this change was concentrated in Asia (IEA, 2017). In SSA, the electrification rate remains low at $45 \%$ in 2018, with nearly 600 million people lacking access, mostly in rural areas (IEA, 2019a). Even the minority with a grid connection can be classed as energy poor, as they suffer from regular power outages and unreliable connections (Practical Action, 2014). The off-grid energy market has the potential to provide technically and financially viable solutions for electrification to both remote households located far from electricity grids and ones unable to afford grid connection. Electricity access can lead to social and economic development and support the delivery of outcomes across all SDGs, highlighting the need to explore off-grid solutions for electrification in SSA (Nerini et al., 2018).

The off-grid market comprises a mix of technologies, with the most appropriate largely dependent on the resources available, geographic, climate conditions, and the institutional framework. The International Energy Agency (2017) notes that decentralised systems, such as solar photovoltaics are a low cost solution, which could be scaled up in SSA. The cost-effective nature of decentralised systems, such as micro-grids, SHSs and pico-solar, has enabled improved access to electricity for rural populations (IEA, 2017). Key components of a SHS are a solar panel, which is usually mounted on a roof and charges a battery that powers various household appliances, including lights and depending on the capacity of the system, televisions. We focus on SHSs in our study, as they are likely to achieve high growth rates, projected at sale rises of $80-90 \%$ over the next five years (GOGLA, 2018). The addressable market for SHSs consists of 310 million people, although the demand and ability to pay for them varies by country (Lighting Global \& World Bank Group, 2020). SHSs are particularly popular in SSA, making up $70 \%$ of the total global sales (GOGLA, 2019). 


\subsection{Gaps in Existing Reviews}

We build on existing reviews of solar energy technologies globally and in SSA (Brunet, Savadogo, Baptiste, \& Bouchard, 2018; Feron, 2016; Lemaire, 2018). Lemaire (2018) reviewed 98 documents, made up of journals, reports and dissertations amongst others, focussing on the impact of SHSs and solar lanterns on households in the Global South. For this assessment, they prioritise social and economic drivers, such as health, education, social networks, finance and livelihood creation. Feron (2016) examines both pico-solar and SHSs in Latin America, Asia and Africa, categorising 126 publications into four headings related to institutions, economics, environment and society. Brunet et al. (2018) review 112 articles on solar energy technologies in the African continent as a whole from 1992-2016 to address the question of how PV solutions more broadly can contribute to sustainable development. We build on this work by focussing specifically on the rapidly growing market of SHSs for SSA and including more recent work, which is required given the rapid expansion of the SHS market (GOGLA, 2019).

\section{Methodology}

The authors conducted a comprehensive literature review on SHSs in SSA. Three databases were used to search for the literature - ScienceDirect, Scopus and Web of Science.

\subsection{Inclusion and Exclusion Criteria}

All research articles, conference papers and review articles published up to and including December 2019 were included. The scope of the study was restricted to papers focussing on SHSs as a dominant topic. Hence, papers looking at the role of SHSs to support cooking or ones comparing micro-grids and electricity grids with SHSs were included in the review, as long as the predominant focus remained on SHSs. Papers that focused on other geographies beyond SSA were excluded. Publications that did not primarily focus on SHSs were also excluded, for instance articles that analysed community solar projects. Finally, papers not published in English were excluded.

\subsection{Search Criteria}

Using the search criteria set out in Table 1, the ScienceDirect search resulted in 69 research articles and review articles, whilst 50 Scopus articles, conference papers and reviews remained after the exclusion criteria was utilised. In Web of Science the "Topic Search" filter was utilised with the same keywords, in the absence of the "Title, Abstract, Keywords" search option. This resulted in 20 articles, proceedings papers and reviews after removing duplicates from the other databases and following the outlined criteria.

In addition to the Table 1 criteria, all three databases were searched for the term "solar system" in place of "solar home system" to ensure that papers that were not using this specific term were also included. Finally, a database of 139 papers that fit the inclusion criteria was created and the articles were uploaded to NVivo, where they were coded and analysed. 


\begin{tabular}{|c|c|c|c|c|}
\hline Database & Search Criteria & Article Type & $\begin{array}{l}\text { Search } \\
\text { Results }\end{array}$ & $\begin{array}{l}\text { Remaining Papers } \\
\text { after inclusion and } \\
\text { exclusion criteria }\end{array}$ \\
\hline $\begin{array}{l}\text { Science } \\
\text { Direct }\end{array}$ & $\begin{array}{l}\text { All ("solar home system*" and } \\
\text { "africa") and Title, Abstract, } \\
\text { Keywords ("solar home system*") }\end{array}$ & $\begin{array}{c}\text { Research } \\
\text { articles \& } \\
\text { Review } \\
\text { Articles }\end{array}$ & 129 & 69 \\
\hline Scopus & $\begin{array}{l}\text { Title-Abs-Key ("solar home } \\
\text { system*") and all ("solar home } \\
\text { system*") and all (africa) and } \\
\text { (exclude (pubyear, 2020)) } \\
\text { and ( limit-to (doctype, "ar") or limit } \\
\text { - to (doctype, "cp") or limit - to } \\
\text { (doctype, "re")) and (limit - to } \\
\text { (language, "English") ) }\end{array}$ & $\begin{array}{l}\text { Conference } \\
\text { Paper \& } \\
\text { Article \& } \\
\text { Review }\end{array}$ & 219 & 50 \\
\hline \multirow[t]{2}{*}{$\begin{array}{l}\text { Web of } \\
\text { Science }\end{array}$} & $\begin{array}{l}\mathrm{TS}=(\text { "solar home system*" and } \\
\text { africa) and Language: (English) }\end{array}$ & $\begin{array}{l}\text { Article \& } \\
\text { Review \& } \\
\text { Proceedings } \\
\text { Paper }\end{array}$ & 83 & 20 \\
\hline & & & 431 & 139 \\
\hline
\end{tabular}

\subsection{Analysis}

The abstracts and conclusions of the 139 papers were reviewed. Building on classifications developed by Schillebeeckx et al. (2012), the publications were categorised into the technology, institutional, viability and user-centric themes. The theme definitions were modified (see Table 2) to fit the specific focus on SHSs and to incorporate costing within the viability criteria as affordability is a well-known barrier for scaling up solar energy (Scott, 2017).

The authors applied a primary and if applicable secondary classification to each reviewed paper. The primary classification highlights the main purpose of the paper, whilst the secondary classification refers to any additional theme examined. The lead author carried out the initial assessment of theme classification for all the publications, which were validated jointly with the second author. During the validation process, papers with both a primary and secondary classification were re-examined by the authors to reach consensus on the classification.

Table 2 Category Definitions (adapted from Schillebeeckx et al. (2012))

\begin{tabular}{|c|l|}
\hline Category & \multicolumn{1}{c|}{ Definition } \\
\hline Technology & $\begin{array}{l}\text { The paper focuses on the design or use of a specific SHS technology or a specific } \\
\text { way of distributing electricity or compares different technologies. }\end{array}$ \\
\hline Institutional & $\begin{array}{l}\text { The paper focuses on policy and governance issues (e.g. access, evaluation) of the } \\
\text { SHS project or on the various partners within the SHS project. }\end{array}$ \\
\hline
\end{tabular}




\begin{tabular}{|l|l|} 
Viability & $\begin{array}{l}\text { The paper focuses on the financial mechanisms used to enable (or disable) financial } \\
\text { viability of the project and cost calculations and comparisons. }\end{array}$ \\
User-centric & $\begin{array}{l}\text { The paper puts the potential or future user of the SHS at the heart of the debate and } \\
\text { investigates their needs, the role of their communities and their resource limitations. }\end{array}$
\end{tabular}

The methodologies used in the papers were reviewed to add towards the understanding of the techniques currently being utilised when analysing SHSs. These were then split into three broad categories: quantitative, qualitative and mixed methods.

\section{Results and Discussion}

\subsection{Background on reviewed papers}

\subsubsection{Journals and articles types}

The most common journals that published the reviewed papers were Energy Policy and Renewable and Sustainable Energy Reviews (Table 3). Out of the literature reviewed, the 94 research articles held the predominant share with $68 \%$ of the analysed documents, whilst the 28 conference papers accounted for $20 \%$ and the 17 reviews for only $12 \%$ of documents.

Table 3 Number and Type of Journal Publication

\begin{tabular}{|l|c|}
\hline \multicolumn{1}{|c|}{ Journal Publication } & Number \\
\hline Renewable and Sustainable Energy Reviews & 13 \\
\hline Energy Policy & 13 \\
\hline Energy for Sustainable Development & 9 \\
\hline Renewable Energy & 8 \\
\hline Energy Research \& Social Science & 8 \\
\hline Energy Procedia 1 & 8 \\
\hline Applied Energy & 5 \\
\hline Journal of Energy in Southern Africa & 5 \\
\hline Refocus & 5 \\
\hline Sustainable Energy Technologies and Assessments & 4 \\
\hline
\end{tabular}

\subsubsection{Publication Date}

The number of papers that have been published on SHSs in SSA increased over the last six years, with 96 out of 139 examined papers published since 2012 (Fig. 1). Fewer papers were published in 2019 compared to previous years highlighting that more research into SHSs is required,

\footnotetext{
${ }^{1}$ Only publishes conference papers
} 
particularly to address knowledge gaps in countries with low electrification rates. In those countries SHSs can fill a gap in energy access and replace lights from kerosene and other fuels.

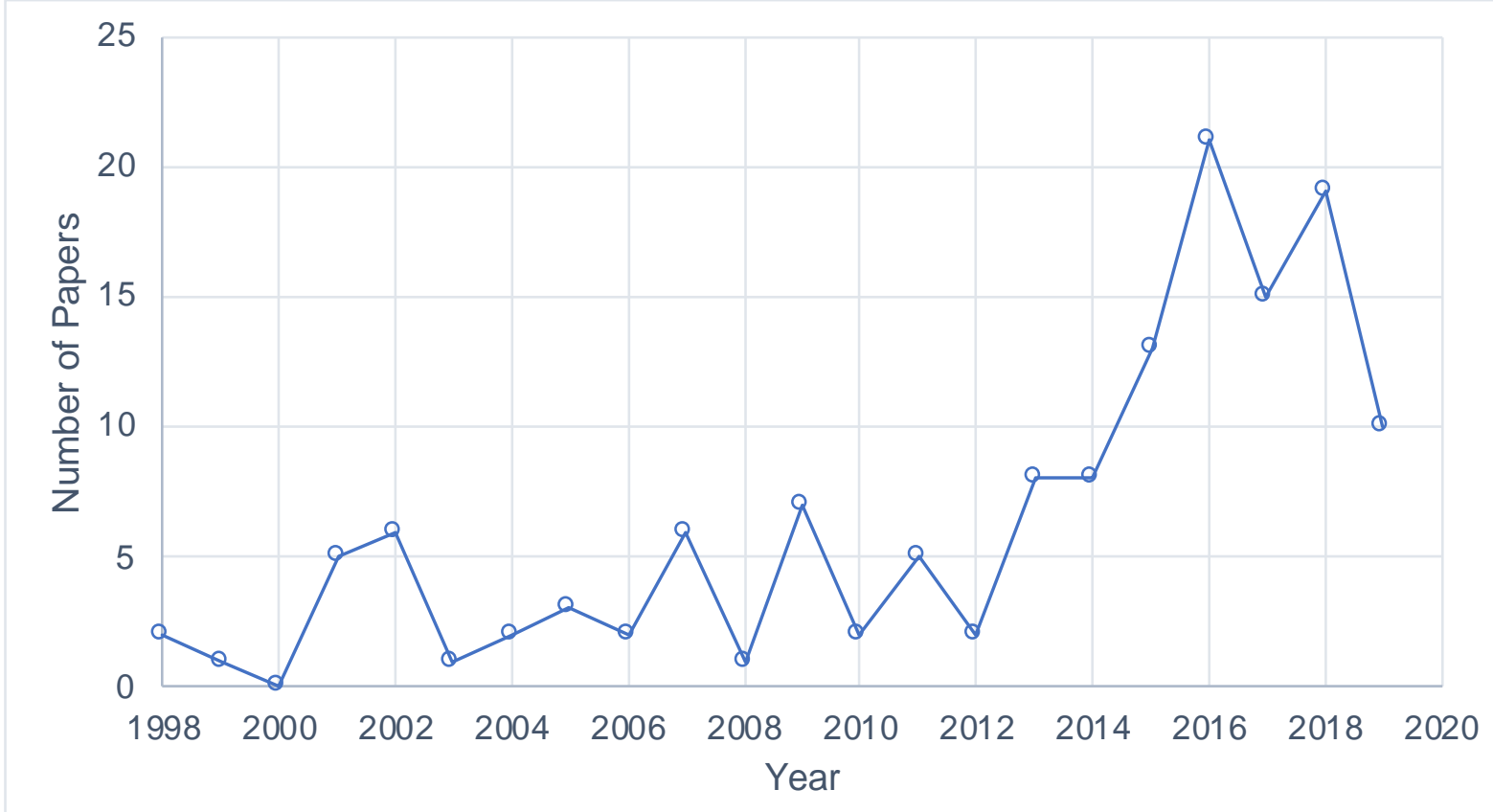

Fig. 1 Dates of Publication

\subsection{Examined Countries}

The reviewed papers focussed on 25 of the 46 SSA countries, showing that South Africa and Kenya far outstripped other countries, in terms of popularity (Table 4). Most papers had country specific case studies, specifically 77 out of 139 papers, with some authors choosing to examine multiple countries. Although, notably Diouf and Avis (2019) selected the Economic Community of West African States (ECOWAS) as their case study and consequentially all 15 members countries were included. The rural electrification rate was chosen for this comparison, as the SHS market is mainly aimed at improving the energy access of rural populations. Overall, Table 4 shows countries examined less often in the reviewed papers have a lower proportion of their rural population electrified, although there are plenty of outliers to this trend.

Table 4 Countries examined in the reviewed literature and their respective electricity access

\begin{tabular}{|l|l|c|c|}
\hline & \multicolumn{1}{|c|}{ Countries } & Number & $\begin{array}{c}\text { Percentage of rural population with } \\
\text { electricity access (2018) (IEA, 2019b) }\end{array}$ \\
\hline $\mathbf{1}$ & Kenya & 20 & $66 \%$ \\
\hline $\mathbf{2}$ & South Africa & 19 & $92 \%$ \\
\hline $\mathbf{3}$ & Uganda & 9 & $11 \%$ \\
\hline $\mathbf{4}$ & Tanzania & 8 & $18 \%$ \\
\hline $\mathbf{5}$ & Zambia & 8 & $<5 \%$ \\
\hline $\mathbf{6}$ & Rwanda & 7 & $44 \%$ \\
\hline $\mathbf{7}$ & Ethiopia & 6 & $32 \%$ \\
\hline $\mathbf{8}$ & Ghana & 5 & $73 \%$ \\
\hline
\end{tabular}




\begin{tabular}{|l|l|l|c|}
\hline $\mathbf{9}$ & Senegal & 4 & $47 \%$ \\
\hline $\mathbf{1 0}$ & Burkina Faso & 4 & $<5 \%$ \\
\hline $\mathbf{1 1}$ & Zimbabwe & 3 & $12 \%$ \\
\hline $\mathbf{1 2}$ & Namibia & 2 & $35 \%$ \\
\hline $\mathbf{1 3}$ & Nigeria & 2 & $34 \%$ \\
\hline $\mathbf{1 4}$ & Côte d'Ivoire & 2 & $32 \%$ \\
\hline $\mathbf{1 5}$ & Botswana & 2 & $27 \%$ \\
\hline $\mathbf{1 6}$ & Lesotho & 2 & $24 \%$ \\
\hline $\mathbf{1 7}$ & Sierra Leone & 2 & $<5 \%$ \\
\hline $\mathbf{1 8}$ & Cape Verde & 1 & $90 \%$ \\
\hline $\mathbf{1 9}$ & Mali & 1 & $20 \%$ \\
\hline $\mathbf{2 0}$ & Togo & 1 & $16 \%$ \\
\hline $\mathbf{2 1}$ & The Gambia & 1 & $15 \%$ \\
\hline $\mathbf{2 2}$ & Guinea & 1 & $12 \%$ \\
\hline $\mathbf{2 3}$ & Guinea-Bissau & 1 & $8 \%$ \\
\hline $\mathbf{2 4}$ & Niger & 1 & $<5 \%$ \\
\hline $\mathbf{2 5}$ & Liberia & 1 & $<5 \%$ \\
\hline
\end{tabular}

Fig. 2 reveals that East and South Africa dominate the map, partly due to their advanced mobile money ecosystems that play a key role in the provision of PAYG services for SHSs (GOGLA, 2018). The strong and active involvement of the private sector may also be drawing academic attention, as it provides case studies and data from projects.

The map also highlights that several SSA countries, especially in Central Africa, are underresearched. This is particularly crucial as many of the countries not represented in Fig. 2 have very low electrification rates. For example, in countries, such as the Democratic Republic of Congo, only $9 \%$ of the population had access to electricity in 2018 and in Central African Republic the rate was lower than 5\% in the same year (IEA, 2019b). In comparison, the countries examined most in the reviewed papers, Kenya and South Africa, had electrification rates of $75 \%$ and $95 \%$ in 2018 respectively (IEA, 2019b). As more SSA countries embrace SHS diffusion to provide energy access, more research will be required to understand context specific challenges of those markets through further research on their viability and institutional frameworks. This increased knowledge could in turn support their scale up of solar energy solutions. The greatest impact would arise by focussing on the countries not identified in this review, such as in Central Africa, where SHS companies are limited and sales are low (GOGLA, 2019). 


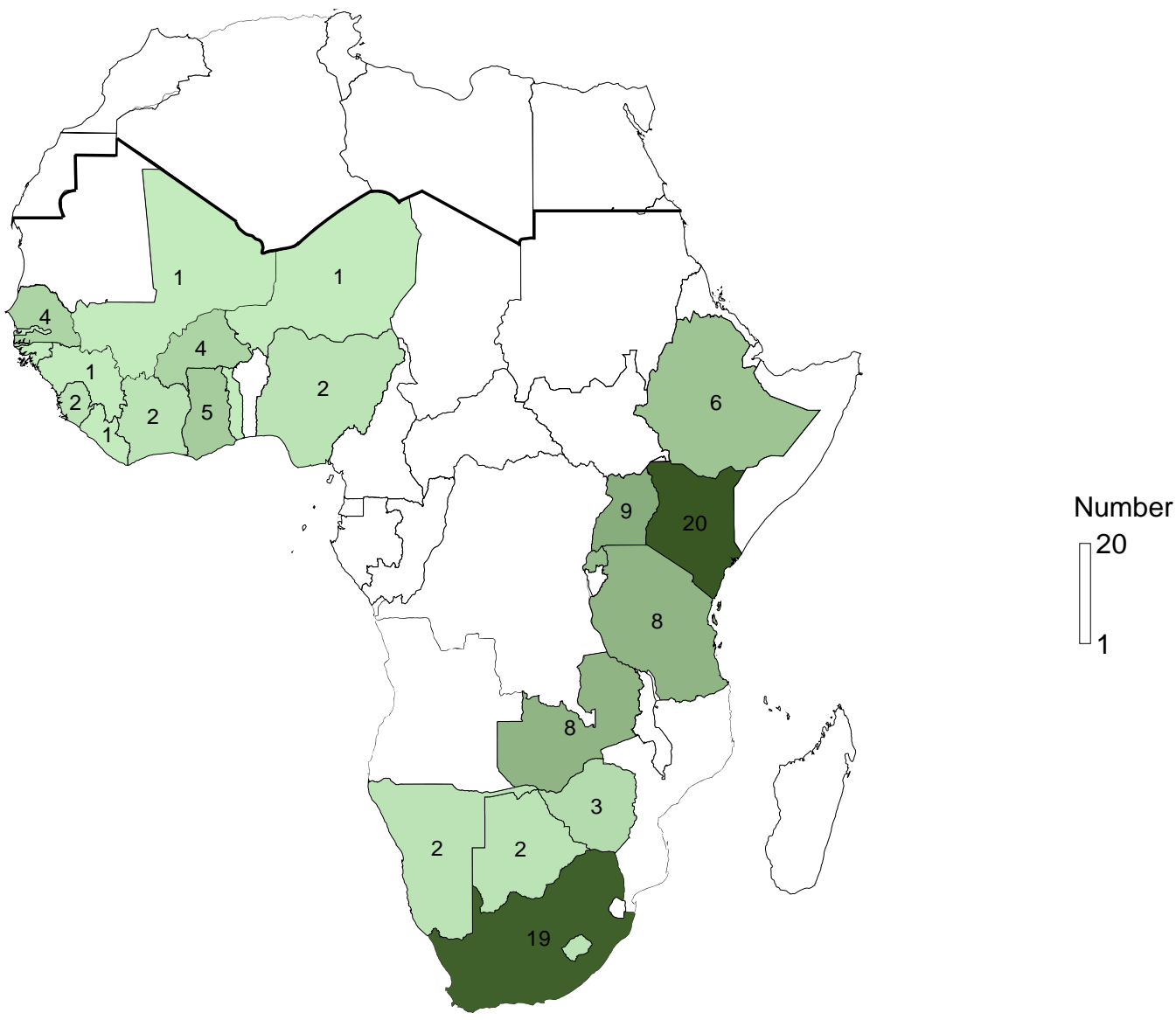

Fig. 2 Countries examined in the reviewed papers

\subsection{Categories}

Out of a total 139 publications, 69 papers had only a primary focus, whilst 70 papers had both primary and secondary classifications (Fig. 3). The most popular primary category was technology. This was closely followed by the user-centric and viability categories, although the latter had a higher secondary presence. Finally, papers on policies and institutions tended to lag behind in the primary category but turned out to be the most common secondary theme. 


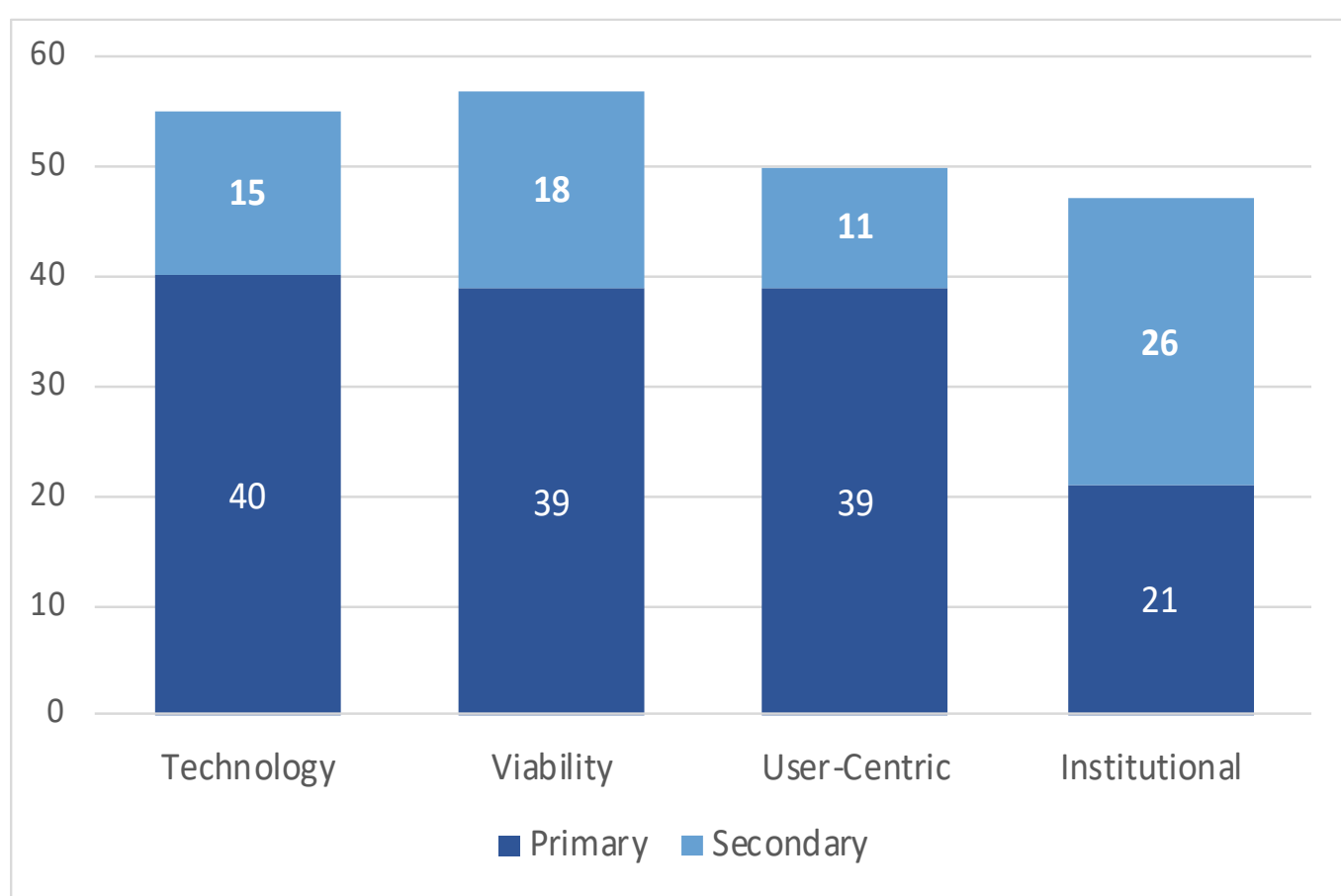

Fig. 3 Number of papers per category and classification

This relatively even split in the three out of four categories shows that a broad range of research is being conducted in this field ranging from reviewing SHS business models to the analysis of battery life-cycle costs. However, the institutional theme was noted as a gap, which could be due to such papers often adopting a top-down level view, discussing a broad range of policies applicable to several technologies. This lack of specificity may have resulted in a few of these papers not meeting our inclusion criteria for this review. Nevertheless, there is a need to examine the institutional framework and policies surrounding SHSs in a more targeted manner.

\subsection{Methods used in the Papers}

The methodologies of each paper were reviewed and classified, where $49 \%$ of the papers utilised qualitative methods, $31 \%$ quantitative and only $20 \%$ used mixed methods. The lower percentage of quantitative methods is striking considering that the most common primary category was technology, which is usually linked to quantitative approaches. A possible reason for this could be the lack of quantitative energy usage data available for SHSs, with only a handful of companies able to collect smart data at scale. More than half of the papers, 74 out of the 139, were classified as case studies indicating reliance on private sector initiatives.

\subsection{Priority Topics}

The most popular topics discussed in the papers have been grouped into four categories: viability, technology, user-centric and institutional. Table 5 includes topics raised in the abstract or conclusion of at least ten papers. 


\begin{tabular}{|c|c|c|}
\hline Categories & Topics & Number of Papers \\
\hline Viability & $\begin{array}{l}\text { SHS business models } \\
\text { Financing } \\
\text { Diffusion of SHS systems } \\
\text { Cost comparison } \\
\text { Affordability } \\
\text { Training } \\
\text { Commercial sustainability } \\
\text { Investment } \\
\text { Company service }\end{array}$ & $\begin{array}{l}\mathbf{3 1} \\
29 \\
\mathbf{2 8} \\
28 \\
27 \\
17 \\
16 \\
13 \\
10\end{array}$ \\
\hline Technology & $\begin{array}{l}\text { SHS design } \\
\text { Battery } \\
\text { Maintenance } \\
\text { Grid versus SHS } \\
\text { SHS quality } \\
\text { Mini-grid } \\
\text { Modelling } \\
\text { Energy generation capacity }\end{array}$ & $\begin{array}{l}\mathbf{2 6} \\
26^{2} \\
\mathbf{2 4} \\
17 \\
14 \\
13 \\
13 \\
11\end{array}$ \\
\hline User-Centric & $\begin{array}{l}\text { Energy demand of end-user } \\
\text { Appliance usage } \\
\text { Social practices } \\
\text { SHS income generation } \\
\text { Customer satisfaction } \\
\text { SHS awareness } \\
\text { Customer knowledge }\end{array}$ & $\begin{array}{l}\mathbf{3 0} \\
\mathbf{2 6} \\
18 \\
17 \\
16 \\
15 \\
14\end{array}$ \\
\hline Institutional & $\begin{array}{l}\text { Barriers to SHS adoption } \\
\text { Local capacity/production } \\
\text { Community engagement } \\
\text { Determinants of SHS adoption } \\
\text { Economic development } \\
\text { GHG emissions/ Climate change }\end{array}$ & $\begin{array}{l}\mathbf{1 9} \\
\mathbf{1 7} \\
13 \\
13 \\
12 \\
10\end{array}$ \\
\hline
\end{tabular}

Two of the top three most popular topics in each category were selected to analyse in detail. In the viability category, 'diffusion of SHSs' was discussed instead of 'financing', as the latter covered similar topics to 'SHS business models'. Maintenance was chosen in the technology category, as the comments made on this issue were deemed more insightful compared to the battery topic.

\subsubsection{Viability}

\subsubsection{SHS Business Models}

The literature focusses on a range of business models being tested in various geographies. Predominantly the traditional sales models of cash and credit, as well as the service models of rent-to-own and fee-for-service, are extensively covered (Friebe, Flotow, \& Täube, 2013a). As the SHS market matures, companies are shifting from a sales approach towards more service-

\footnotetext{
${ }^{2}$ Includes mentions of battery life, battery type, battery capacity and battery sizing
} 
based models (Friebe, Flotow, \& Täube, 2013b). This is due to the SHS affordability challenge being partly alleviated by the emergence of innovative pay-as-you-go (PAYG) payment schemes, which can ease credit constraints (Abdul-Salam \& Phimister, 2019; Adwek et al., 2019; Lay, Ondraczek, \& Stoever, 2013). PAYG allows customers to pay in instalments over time to either own the SHS (rent-to-own) or for continued use of the SHS (fee-for-service) (GOGLA, 2019). SHS customers using PAYG are more likely to continue their payments in the long run because it offers them greater flexibility - only having to pay when they can afford to (Conway et al., 2019). It also provides companies with a stronger link to customers compared to a cash approach, enabling them to sell more appliances to their users in the future (Adwek et al., 2019).

Increasing interest in these PAYG SHS business models was noted in the reviewed literature, particularly in fee-for-service schemes. Fee-for-service is perceived to be a more affordable and sustainable approach, with the potential to provide customers with long-term high quality services, due to the accompanying maintenance schemes (Nieuwenhout et al., 2001). However, because it is a more complex arrangement, a contract with a SHS provider is usually required. Customers often do not understand the terms and conditions, which can lead to future disappointment and even repossession of their SHSs, thus reducing energy access (Lemaire, 2011). Despite lowering the high upfront costs faced in cash based models, the fee-for-service approach is still deterring low-income households that are unable to afford regular payments. Ketlogetswe and Mothudi (2009) note that in Botswana, 37\% of participants on the fee-forservice model could not cover payments. This implies that in some countries, the fee-for-service model will need to be subsidy-dependent to reach a wider customer base. These subsidies might also help SHS companies reduce their default risk (Barrie \& Cruickshank, 2017; Duke, Jacobson, \& Kammen, 2002).

As each country is different, business models have varying levels of success. This is illustrated by Kovic (2010) who examined technology transfer projects in Zambia and Kenya and found that in the former the fee-for-service business model worked well, whilst in the latter it would have been unsuccessful as a market approach, where individuals buy systems outright, was more effective. This was due to institutional differences in the countries, in particular households' ability to access loans (Kovic, 2010). It is thus important to showcase business models of projects that are viable, sustainable and transparent, allowing others to trial them (Martinot, Cabraal, \& Mathur, 2001).

Moreover, the business model should reflect which customers are targeted, as rural households do not have the same information access and technical assistance as their urban counterparts (Pode, 2013). In urban areas, a 'sale and forget' model can be acceptable, where the customer just receives the product they paid for, without additional services (Pode, 2013). However, in rural areas a more structured service approach is required, including training and maintenance.

A business model success framework, developed by Scott (2017, p. 50), comprises: "community interaction; partnerships; local capacity building; and addressing barriers unique to the off-grid market", such as developing distribution networks and finance. All the framework components are based on local cooperation, highlighting its importance in a successful business model. 
Hence, it is crucial for a SHS company to develop local cooperation, understand the nuances of different country contexts and tailor their approach to customers, depending on their income, rural or urban setting and prior SHS knowledge.

\subsubsection{Diffusion of SHS systems}

Multiple studies examined factors increasing SHS diffusion (Barrie \& Cruickshank, 2017; Green \& Erskine, 1999; Hansen, Pedersen, \& Nygaard, 2015; Katikiro, 2016; Kebede, Mitsufuji, \& Choi, 2014a; Lay et al., 2013; Nieuwenhout et al., 2001; Ondraczek, 2013; Opiyo, 2019; Posorski, Bussmann, \& Menke, 2003; Smith \& Urpelainen, 2014; Zhang, 2014). The main advantage of SHS diffusion is to improve the living standard of off-grid households and climate protection by transitioning away from kerosene (Posorski et al., 2003).

The visibility of new SHS installations is a key diffusion factor, as it increases the number of SHS purchases and plays a larger role than advertisements and word-of-mouth in a household's adoption decision (Opiyo, 2019). Lay et al. (2013) observed that the proximity of SHS installations to a potential customer positively influences their likelihood of adoption. In essence, the visibility of SHSs increases the local adoption rate and this clustering of SHS users leads to a rising chance that nearby households become customers. This reinforcing cycle is partly due to growing awareness of SHSs and knowledge resulting from more adoptions (Ondraczek, 2013). A knowledge transfer can also take place from urban to rural areas through family members for instance, potentially impacting SHS adoption (Smith \& Urpelainen, 2014). One way of fostering the diffusion process in an area could thus be for governments to showcase SHSs on public buildings, such as schools and hospitals (Green \& Erskine, 1999).

Understanding community perceptions of new technologies is important to aid their transition to renewable energy (Katikiro, 2016). Particularly, as trust in the technology amongst the community is crucial for its diffusion, which can be built by providing good after-sales services (Kebede et al., 2014a). Good quality SHSs and services are usually associated with reputable companies. However, in Burkina Faso, the SHSs that were quality verified and associated with a brand were adopted less frequently than non-branded SHSs (at rates of $8 \%$ and $36 \%$ respectively), possibly as both systems were similar, in terms of durability and customer satisfaction, but different in price, with the branded option more expensive (Bensch, Grimm, Huppertz, Langbein, $\&$ Peters, 2018). However, further research is needed to ascertain whether households prefer purchasing non-branded products in other geographies and possible motivations for doing so. Governments should provide quality dependent subsidies for manufactures to ensure better quality products for consumers, branded or not, as it benefits SHS diffusion and community trust in the technology (Zhang, 2014).

The payment method also plays a large role in adoption, where the PAYG model is hailed as the most successful option for boosting SHS dissemination (Adwek et al., 2019). This is echoed by Barrie and Cruickshank (2017), who state that PAYG improves SHS adoption rates, despite raising the actual cost of diffusion by increasing the payment complexity compared to a retail approach. Moreover, it is often dependent on the mobile literacy of households, as payments are usually made via mobile phones, potentially excluding households without phones or mobile payment knowledge (Adwek et al., 2019). PAYG is also highly reliant on good mobile network 
connectivity, which remains an issue in many SSA countries and requires improvements to support SHS diffusion (Adwek et al., 2019).

Hence, the SHS diffusion can be increased through more installation clusters and the accompanying visibility of SHSs, as well as growing SHS awareness, increased community trust in the technology and expanding PAYG adoption.

\subsubsection{Technology}

\subsubsection{SHS Design}

The general design and sizing of SHSs, along with recommendations for future system designs were the most common topics in the technology category.

System designers need to consider households' behavioural patterns to ensure that customers can use SHSs effectively and sustainably. This includes providing longer cables for lights to be used in other rooms and assist with activities, such as cooking (Stojanovski, Thurber, \& Wolak, 2017b). These needs are difficult to gauge without conducting studies with SHS users to find out how they use the system in practice.

The non-optimal energy usage of households should be noted by system designers. This includes understanding how the battery is affected by constant deep discharging when systems are used to their limits (Tillmans \& Schweizer-Ries, 2011). This is crucial for choosing the right battery capacity and avoiding the incorrect sizing of various components (Campana et al., 2016; Monyei, Adewumi, \& Jenkins, 2018; Narayan et al., 2018). Many households will still overuse their SHS, although measures, such as an external battery state of charge display and appropriate training could reduce the amount of power cuts (Gustavsson, 2007b). However, Hajat et al. (2009) propose a more stringent approach by directly limiting night-time usage to curb system overuse, thereby potentially increasing battery lifetime.

External conditions, such as the effect of solar panel shading and a country's solar spectrum are vital to consider when designing solar panels, as their optimisation could improve energy generation capacity (Simon \& Meyer, 2008; Ubisse \& Sebitosi, 2009). For example, a higher capacity system was required in one region of South Africa compared to another, in order to generate the same amount of energy, which was attributed to solar irradiance differences (Azimoh, Klintenberg, Wallin, \& Karlsson, 2015b).

The system size of SHSs is closely connected with the energy consumption of the household, though often the systems are not appropriately sized for users and are therefore unable to meet their energy needs (Azimoh, Klintenberg, Wallin, \& Karlsson, 2015a; Azimoh, Wallin, Klintenberg, \& Karlsson, 2014; Feron, 2016; Opiyo, 2016). For instance, Monyei et al. (2018) note that the fixed SHS capacity prevents households from acquiring new appliances and increasing their energy usage, as the system is often unable to cope with higher loads. This needs to be balanced against oversizing the SHS, which can result in customers paying additional money for a system that outstrips their energy needs. Households should have access to a wider 
range of SHS capacities to enable them to choose an appropriate size for their needs, which might encourage higher adoption rates (Nieuwenhout et al., 2001).

Hence, system designers must consider household's behaviour and needs, including non-optimal energy usage, as well as external conditions, such as solar irradiance, when devising SHSs. Companies should also diversify their offering to include a wider range of SHS capacities.

\subsubsection{Maintenance}

The provision of maintenance to SHS users over a longer period is one of the key success factors for business models (Friebe et al., 2013b). However, receiving continuous maintenance support is a challenge for many users, particularly if they bought their systems outright (Mapako, 2005). Even if customers went through a rent-to-own scheme they face issues with system repairs, particularly after possession, as many SHS companies design their systems to be tamper-proof for warranty purposes. This complicates repairs undertaken by technicians not employed by the SHS provider and usually results in the warranty being waived if the user is still a customer (Cross \& Murray, 2018). Households that are not able to repair their SHS, might abandon it for their previous energy source. However, Pode (2013) highlights a scheme, where households can purchase additional warranties, after their initial loan period, to receive further maintenance support from energy providers.

The substantial maintenance costs are a key challenge, which arise due to "low user densities, equipment failure, poor handling and a complete lack of accountability" (Schelling et al., 2010, p. 1). The latter two issues are operational, as companies can devise a regularly monitored maintenance procedure for all technicians to improve handling issues and accountability. Equipment failure is a common problem, where batteries in particular often need replacing. As the highest cost component in SHS systems, they drive up maintenance costs (Okou, Mwaba, Khan, Barendse, \& Pillay, 2009). Hajat et al. (2009) argue that batteries are worth repairing and regularly maintaining, as it leads to SHSs with longer lifetimes and better quality energy supply for households. Moreover, this maintenance contributes to sustainability efforts, although recycling remains an issue in this growing sector (Adwek et al., 2019).

There is scope to use more durable systems, such as flywheel battery storage (Okou, Sebitosi, \& Pillay, 2011) or maintenance-free systems (Diouf \& Pode, 2013; Zubi, Dufo-López, Pardo, \& Pasaoglu, 2016) with the use of quality components. Although, there are trade-offs with their increased costs and further evaluation is required to assess their performance.

Training local technicians to be proficient in repairs and minor maintenance is vital for meeting household demand as often households and technicians lack technical knowledge about SHSs (Azimoh et al., 2014; Scott, 2017). Timely maintenance is crucial, as delays in repairing systems have negative consequences for the households waiting and the wider reputation of the technology (Green \& Zwebe, 2006). This is especially relevant in SSA, where SHSs have already gained unfavourable perceptions due to the insufficient high quality maintenance schemes available to SHS customers (Conway et al., 2019). Although, the emergence of smart SHSs has enabled companies to remotely monitor SHSs and proactively handle technical faults by contacting the customer or deploying local technicians (Bisaga et al., 2017). 
Hence, maintenance is crucial to ensure households' continual usage of SHSs, although high maintenance costs and tamper-proof systems can hamper maintenance efforts. Such barriers can be overcome by increasing the number of locally trained technicians and installing smart SHSs.

\subsubsection{User-Centric}

\subsubsection{Energy demand of end-user}

Multiple papers examined household's energy demand, focusing on the actual load profiles of off-grid system users, the usage pattern of SHSs and demand fluctuation with time (Kulworawanichpong \& Mwambeleko, 2015; Soltowski, Bowes, Strachan, \& Anaya-Lara, 2018).

A few studies recommend raising household's low energy demand before connecting them to the electricity grid to recover the high investment costs of grid extension (van der Plas \& Hankins, 1998; van der Vleuten et al., 2007). In the meantime, people's small energy needs can be met by PV systems (van der Vleuten et al., 2007). However, there is some consensus that energy demand is likely to increase, with energy consumption rising over time (Levin \& Thomas, 2016; van der Vleuten et al., 2007). Chattopadhyay et al. (2015) refers to the history of electrification when claiming that demand will grow rapidly, due to households purchasing more appliances. However, often households can be constrained in their SHS choice by donor-funded projects, potentially restricting their energy demand growth due to a low capacity that is unable to power their appliances (Nieuwenhout et al., 2001). Moreover, in a study by Kennedy et al. (2019) most SHS customers were low-income households, which they argued was directly related to their low energy demand. Bisaga and Parikh (2018) did not detect an increase in demand over time in their Rwandan study of power consumption data, which they partly accredited to energy stacking practices making accurate measurements challenging. However, they found that access to small amounts of energy was still transformational, particularly for low-income households, who could replace polluting lighting sources with SHSs (Bisaga \& Parikh, 2018).

The question of whether energy usage of SHS customers increases over time remains and the answer will be highly end-user dependent, i.e. household or business, as well as context dependent and should be studied further.

The actual usage pattern of SHSs is covered extensively in the literature. Households have issues with non-optimal utilisation of SHSs, particularly overutilisation (Azimoh et al., 2015a, 2014; Lemaire, 2009). This is accredited to households' lack of knowledge on how to sustainability use these systems, thus necessitating training (Azimoh et al., 2015a; Hajat et al., 2009; Tillmans \& Schweizer-Ries, 2011). Gustavsson and Mtonga (2005) discovered that SHS users realised within a year how to avoid power cuts, although they still struggled with overusing the system, which negatively affects battery lifetime. This issue stems from household needs, with SHSs used most often in the mornings and evenings (Gustavsson, 2007b). This means that households rarely utilise the real-time energy produced in the daytime and instead drain their battery in the evenings. Soltowski et al. (2018) discovered in their Rwandan case study that $65 \%$ of SHS generation was not utilised. This provides an opportunity to interconnect customers and form 
micro- or mini-grids to utilise this excess energy, which is a growing subject with a lot of potential.

Most SHS users currently use low energy amounts that are sufficiently met by off-grid systems, although their energy demand may rise over time. Moreover, several papers focus on the usage patterns of customers, particularly the continuing problem of overutilisation.

\subsubsection{Appliance usage}

Appliances are at the forefront of SHS studies, as households need energy efficient appliances for productive energy use. For households, the attraction of a SHS did not purely lie in better quality lighting but in owning other appliances, particularly televisions (Brunet et al., 2018; Gustavsson \& Ellegård, 2004; Wamukonya \& Davis, 2001). Gustavsson (2007b) highlights that televisions are commonly acquired after purchasing the SHS, whilst appliances, such as radio cassette players are often present in both non-solar and solar households. Green and Erskine (1999) also found that customers' highest priority appliances for the future were televisions and stoves. Park and Phadke (2017) believe that demand for televisions will continue rising with higher electrification rates and lower prices. However Bisaga and Parikh (2018) note that new appliance acquisition among SHS users in Rwanda, beyond lights and phone chargers, remained low in rural settings.

Several authors refer to the educational benefits that can be derived from appliances, such as lights (Diallo \& Moussa, 2019). Ngetha et al. (2015) found that 93\% of households used their SHS lighting to aid studying or work efforts. Several authors highlight the increased studying time for children due to the introduction of the SHS, particularly the accompanying lights (Bisaga \& Parikh, 2018; Diouf \& Pode, 2013; Ellegård, Arvidson, Nordström, Kalumiana, \& Mwanza, 2004; Gustavsson, 2007a; Gustavsson \& Ellegård, 2004; Hakiri, Moyo, \& Prasad, 2016; Wamukonya \& Davis, 2001). Televisions and radios provide access to news, leading to more informed households and bringing users closer to the outside world (Gustavsson, 2007a; Hakiri et al., 2016). However, a study by Green and Zwebe (2006) does not show any more homework completed after introducing the SHS. Furthermore, Lemaire (2018) highlights that the quantifiable lighting advancements only have a marginal effect on school year completion rates, whilst conceding that studying conditions do improve.

The general benefits of appliances were discussed, including the time saved by charging phones at home (Barrie \& Cruickshank, 2017). Jacobson (2007) highlights that in Kenya solar had a significant impact in supporting mobile phone usage growth in the whole society. Furthermore, these appliances provide comfort, safety and food security to the SHSs users, which are difficult to quantify but crucial to consider when implementing a project (Hirmer \& Guthrie, 2017).

Hence, papers have discovered a high demand for appliances, particularly lighting and television, offering social benefits, such as improvements in studying time and perceived safety. 


\subsubsection{Institutional}

\subsubsection{Barriers to SHS adoption}

Several barriers of SHS diffusion were noted and broadly categorised as affordability, inadequate knowledge, grid encroachment and operational and institutional challenges.

Multiple authors highlighted affordability as a key barrier, since households can lack insufficient income to cover the high initial cost of the system and keep up with regular payments (Brown, Leary, Davies, Batchelor, \& Scott, 2017; Brunet et al., 2018; Glemarec, 2012; Kulworawanichpong \& Mwambeleko, 2015; Scott, 2017; Uddin, Prinsloo, Marco, \& Jennings, 2017). This is heightened by the lack of payment flexibility and the absence of financing for rural households (Pode, 2013). A case study by Ketlogetswe and Mothudi (2009) found that low household income and seasonal migration for agricultural purposes has contributed to nominal adoption rates in Botswana.

Inadequate consumer knowledge about SHSs is another impediment, which can often lead to non-optimal usage of the system resulting in reduced customer satisfaction (Azimoh et al., 2015a; Scott, 2017). Bisaga et al. (2018) concur that the lack of user awareness is a barrier, particularly as it results in end-users being less likely to communicate their energy needs with relevant stakeholders that design effective business models and policies.

The operation and maintenance considerations of SHSs can become a barrier, if companies face issues with the resilience of their equipment and installations, particularly in the absence of proper quality control, potentially causing high operational costs (Azimoh et al., 2015a; Brunet et al., 2018; Scott, 2017). However, Zubi et al. (2016) argue that the implementation issues for SHSs are low, as they require only moderate investment and minimal technical support.

Grid encroachment is also identified as a barrier (Azimoh et al., 2015a). Through a study in five East African nations, Dugoua and Urpelainen (2014) highlight that the proximity of the electricity grid to households has a negative impact on their desire to purchase a SHS, as they have higher hopes for future connection to the grid and would thus reject temporary solutions, such as SHSs. From a broader perspective, the cost of fossil fuels, such as kerosene or oil, as well as urban migration can act as barriers to SHS adoption (Adwek et al., 2019; Brunet et al., 2018). Moreover, the institutional culture within donor organisations was cited as a barrier to interacting with SHS companies, as they favour low-risk projects that provide swift and extensive impacts in a short time frame (van der Vleuten et al., 2007). However, this is at odds with most SHS projects, which could thus lead to companies facing difficulties to sustain their operation.

Hence, barriers to SHS adoption include affordability, inadequate knowledge about SHSs, high operation costs, grid encroachment and the quick success culture engrained within many donor institutions.

\subsubsection{Local Capacity \& Production}

Local capacity and production is an emerging topic with studies covering the three areas of capacity building, support of local entrepreneurs and maintenance. 
One of the four components of a successful business model is local capacity building (Scott, 2017). Filling gaps in supply chains and providing dissemination channels for sales and repair, as well as education are important (Scott, 2017). This could involve training people in the community to be installers, facilitators or part of the maintenance team through skills transfer (Green, Wilson, \& Cawood, 2001). Albeit, the sustainability of such schemes is a challenge due to the low rates of payment and lack of accreditation provided (Green et al., 2001). Another route for building capacity is knowledge exchange through educational organisations to increase local expertise (Lemaire, 2011). This is crucial to foster more research, increase capabilities of these organisations and support local entrepreneurs.

Utilising local talent is key, where Kebede et al. (2014) argue that international companies should partner with local organisations in lieu of setting up their own branches, as local organisations have easier access to rural households and thereby can be more successful in disseminating products. Moreover, supporting local entrepreneurs, who have already developed a decentralised energy infrastructure would also improve project's sustainability (van der Vleuten et al., 2007).

Hansen et al. (2015) find that the local presence of component suppliers and champions partly explain higher SHS diffusion rates in Kenya, as opposed to Uganda and Tanzania. Access to spare parts and technicians at the local level is vital to ensure customer satisfaction (Steel, Anyidoho, Dadzie, \& Hosier, 2016). Cross and Murray (2018) emphasise that often countries already have a maintenance ecosystem in place, where repurposing and reutilisation contribute to people's livelihoods. It is important to leverage the existing capacity of the market and incorporate it into companies' supply chains, instead of setting up separate collection schemes.

The potential of local production is highlighted in several papers (Brown et al., 2017; Ellegård et al., 2004; Kebir \& Philipp, 2016; Moner-Girona, Ghanadan, Jacobson, \& Kammen, 2006; Nygaard, Hansen, Mackenzie, \& Pedersen, 2017). Nygaard et al. (2017) demonstrate its opportunity for fostering national innovation in the solar field. Smaller local companies struggle procuring the necessary technologies through international competitive tender, which requires policy attention, if governments want to foster local production (Ellegård et al., 2004).

Hence, local capacity building through skills transfer and knowledge exchange is key, although it is important to partner with local organisations who have existing distribution channels and maintenance ecosystems in place.

\section{Policy Implications}

\subsection{Policy instruments}

\subsubsection{Financial support}

Affordability is a theme throughout the energy access literature and multiple studies highlight the importance of financial support to improve it (Azimoh et al., 2015a; Glemarec, 2012; Hansen et al., 2015; Kebede et al., 2014a; Lemaire, 2009; Nygaard et al., 2017; Ondraczek, 2013). Most 
electrification projects required public resources and Glemarec (2012) supports providing financing where needed to widen the reach of modern energy sources, such as SHSs.

Financing schemes tend to be popular with governments, where Nygaard et al. (2017) observed that all the SSA countries they examined were in favour of them. For instance, finance loans and credit schemes have been successfully used by governments to improve affordability for both SHS purchasers and suppliers and should thus be expanded further (Hansen et al., 2015; Ondraczek, 2013). Moreover, governments could also support customers who want to start a business around their SHS, potentially improving the household's payment capacity (Azimoh et al., 2015a). This support could be financial or through an improved enabling framework.

\subsubsection{Subsidies}

Several studies promoted setting up a subsidy scheme or increasing it further to promote solar energy (Green et al., 2001; Ketlogetswe \& Mothudi, 2009; Lay et al., 2013). This includes using subsidies to support entrepreneurs building their distribution channels, as well as manufacturers that produce quality products (Nieuwenhout et al., 2001; Zhang, 2014). To support local production, subsidies for solar modules could have a price ceiling, based on local market prices, whilst other SHS components remain unsubsidised (Nieuwenhout et al., 2001).

There is scope to reform existing subsidy schemes to levelise government's existing subsidies for grid-based electrification, as they distort cost comparisons between SHSs and electricity grid connections for households (Wamukonya \& Davis, 2001). Another option could be to divert fossil fuel subsidies and reward carbon abatement efforts, such as SHS schemes, instead (Zubi et al., 2017). In practice, this is difficult to achieve, partly due to government lobbying from fossil fuel companies.

Subsidies' lack of sustainability and potential negative long term impacts on the solar market were discussed (Smith \& Urpelainen, 2014; Taele, Mokhutšoane, Hapazari, Tlali, \& Senatla, 2012). Not all governments have the resourcing to subsidise SHSs and innovative multi-sectoral partnerships need to be explored. Conway et al. (2019) argues that if SHS customers pay affordable co-payments alongside a subsidy it would provide a sustainable method of electrification for many households. However, Monyei et al. (2018) highlights that subsidies would need to consider the depreciation and inflation indices of SHSs over their lifetime to ensure that users' costs do not rise to an unsustainable level.

\subsubsection{Taxes and tariffs}

Key policy instruments include taxes, tariffs and import duties. Governments could provide an enabling environment through taxation and regulations to improve affordability (Ondraczek, 2013). For example, tax reductions or exemptions for SHS equipment or solar investments could lead to lower household costs (Adwek et al., 2019; Diallo \& Moussa, 2019; Nygaard et al., 2017). To fund this, governments could raise taxes on carbon-intensive fuels to create a level playing field with SHSs, in terms of costs (Lay et al., 2013).

Import duty exemptions and value-added taxes (VAT) for solar system components have successfully been utilised in the SHS market to increase diffusion (Hansen et al., 2015). 
Moreover, rationalising VAT, import duties and tariffs ensures that all possible electrification routes have an equal opportunity, potentially increasing SHS adoption (van der Plas \& Hankins, 1998). It should be noted that most SHS companies have little scope to change their prices and thus governments should link any rise in tariffs with corresponding exchange rate changes and inflation levels (Lemaire, 2011).

A number of policy instruments for promoting energy-efficient appliances were recommended by Park and Phadke (2017, p. 107) including: "awards, bulk procurement, incentives, and energy labels". Supporting energy efficient appliances is crucial, as they enable customers to maximise their use of the generated energy.

\subsection{Standards and regulations}

A few papers discussed quality standards for products, although most of these expressed the need for their establishment, showcasing that more work is required in this area to reduce the number of low-grade solar products (Adwek et al., 2019; Brunet et al., 2018; Nygaard et al., 2017). Duke et al. (2002, p. 497) suggest that quality standards should apply both nationally and internationally and balance "issues of quality, cost, economic development and consumer choice". In practice, the enforcement of these standards remains low even though most governments recognise lowquality products as a problem (Nygaard et al., 2017). Beyond the SHSs themselves, the accompanying appliances should also adhere to quality standards. For instance, a market could be created where energy efficient appliances, compatible with SHSs, that meet quality standards can be sold. This enables customers to only purchase high quality products that actually work with their SHS and are thus more sustainable and potentially cost-effective (Stojanovski, Thurber, \& Wolak, 2017a).

Regulations tend to focus purely on the large-scale solar photovoltaics market, whilst the smaller counterparts, such as the SHS market often lack specific government regulations, despite the large differences between sectors (Quansah, Adaramola, \& Mensah, 2016). Moreover, solar photovoltaics, SHSs and mini-grid solutions should also be specifically integrated into existing electrification efforts (Azimoh, Klintenberg, Wallin, Karlsson, \& Mbohwa, 2016; Martinot et al., 2001). Adwek et al. (2019) argues that this integration is crucial to support solar companies. Bisaga et al. (2017) suggest setting up a regulatory framework that monitors and evaluates offgrid system performance, which could track underperformers and provide needed oversight into the off-grid market.

\subsection{Institutional frameworks}

A few studies highlight the importance of supportive enabling frameworks in the diffusion of SHSs, which include policy, regulation and market development (Nygaard et al., 2017; Pailman, Kruger, \& Prasad, 2015).

Most countries need to undergo structural changes to reduce the barriers to clean energy technologies, specifically in the institutional, economic and legal domains (Katikiro, 2016). However, the lack of strong institutions in many developing countries have been hindering the electrification progress (Feron, 2016). 
An institutional framework that maps key stakeholders and the role they play in the SHS market should be created (Lemaire, 2011). Based on this, a platform could be built connecting system builders and actors and enabling the provision of institutional support to fill any gaps (Kebede, Mitsufuji, \& Choi, 2014b). Moreover, this platform allows key players to showcase successful pathways for others to follow, potentially reducing newcomers' entry risk in the SHS market (Kebede et al., 2014b).

\section{Future Research Suggestions}

\subsection{User Centric}

There is a need to expand the remit of future surveys, including examining the role of social networks in technology adoption (Smith \& Urpelainen, 2014) and further analysing household's SHS usage (Kennedy et al., 2019; Nieuwenhout et al., 2001). Moreover, energy use determinants, particularly income generating activities, require additional research (Bisaga \& Parikh, 2018).

Future studies measuring impact, included calls to conduct large quantitative studies examining the effect of SHSs on children's education, as well as the relationship between using SHSs, better health and indoor air quality (Lemaire, 2018). The social impact of solar could be studied by identifying the inequalities between households, in terms of their ability to pay and technological literacy (Lemaire, 2018). The effect of introducing SHSs on household's cultural traditions could also be assessed through associated behaviour changes (Brunet et al., 2018; Friebe et al., 2013a). Azimoh et al. (2015a) highlight the value of conducting baseline studies to enable comparisons between the socio-economic conditions before and after the introduction of SHSs.

Other areas for future research are SHS adoption determinants and characteristics. Barrie and Cruickshank (2017) highlight that adoption is country and context specific and recommend comparing different demographic characteristics, such as gender and wealth. Lay et al. (2013) found no correlation between being connected to the grid and purchasing a solar system and suggest a separate re-examination of the two effects.

\subsection{Institutional}

More research on the political and sociocultural issues surrounding energy access is needed, requiring interdisciplinary approaches (Rolffs, Ockwell, \& Byrne, 2015). Moreover, multiple countries require examination to determine a global adoption theory for SHSs (Smith \& Urpelainen, 2014).

Comparative research on technology innovation systems in different countries is required to identify and understand the role of innovation system builders in increasing SHS adoption (Kebede \& Mitsufuji, 2017; Kebede, Mitsufuji, \& Islam, 2015). Governments and donors are two such actors, which often offer support to projects, although research on the impact of this support across countries is limited (Hansen et al., 2015).

Further examination of the solar industry's process for local capacity building is required (Hansen et al., 2015). Research questions on how key stakeholders' knowledge deficits affect the 
performance and lifetime of SHSs are posed by Tillmans and Schweizer-Ries (2011), who also wonder whether it influences customers' willingness to purchase SHSs.

Companies' social responsibility strategy around SHS distribution should be examined, as many may not offer key after-sales services to customers, such as training (Brunet et al., 2018), although the impact of these after-sales services on uptake and household usage still require further research (Kebede et al., 2014a). Finally, SHS companies' increased use of smart systems and the accompanying household data raise questions around customer data privacy and management issues, which ought to be scrutinised (Bisaga et al., 2017).

\subsection{Viability}

More research is required on the added value of each electrification option, specifically SHSs, solar lanterns, mini-grids and electricity grid connections (Lemaire, 2018). Their potential for direct poverty alleviation warrants more attention, as in the case of SHSs this has often been used as a reason to scale up SHS distribution (Stojanovski et al., 2017a). Lee and Callaway (2018) argue that the impact of falling solar costs on grid tariffs should be examined, which may affect the added value of grid connections.

Finally, more research is needed to understand the large discrepancies in SHS installation costs across SSA (Lee \& Callaway, 2018). This may enable policy makers to learn some key lessons from both the low- and high-cost case studies.

\subsection{Technology}

Energy efficiency of solar systems is a growing field with more research required on efficient electrical appliances that could lower energy demand (Hajat et al., 2009). For example, Park and Phadke (2017) call for studies examining the technical side of efficient off-grid televisions, such as quality reviews or interoperability.

Performance monitoring is crucial to ensure that systems are functioning as planned and to aid the creation or development of standards. This includes monitoring the product quality in the field, alongside laboratory tests (Nieuwenhout et al., 2001). For example, additional research comparing the different battery technologies across various indicators, such as estimated lifetimes, will be required in the future (Narayan et al., 2017).

Nowadays smart technologies also enable practitioners to assess performance of systems on a real-time basis from a distance (Bisaga et al., 2017). Simulations can also be used instead of real world implementations. Soltowski et al. (2018) calls for future research to investigate the viability of SHS interconnections through simulations.

\section{Conclusion}

This literature review examined 139 papers that focussed on SHSs in SSA countries. Based on content analysis, the papers were categorised into four themes: institutional, technology, viability and user-centric. So far the primary focus of studies has been on technology, closely followed by the user-centric and viability categories. Despite institutional topics being the most common 
secondary theme in papers, it was far less likely to be the focus of studies. More research is therefore needed to specifically examine the policy and governance issues surrounding SHSs. The most popular topics discussed included SHS business models, SHS design, the energy demand of end-users and barriers to SHS adoption. Almost half of the reviewed papers utilised qualitative methods, whilst only $20 \%$ used mixed methods indicating data gaps, which may be filled by the emergence of more SHS usage data.

The reviewed papers highlight gaps for future research. This includes more studies on household usage of SHSs and its impacts, as well as SHS adoption determinants and characteristics. A greater knowledge base is needed on how the solar industry is building local capacity. The social responsibility strategies of SHS companies should be examined, in terms of their after-sales services and data privacy policies. Performance and quality monitoring will need to be improved as countries shift towards adoption of consistent standards. Finally, this review highlighted the need for more research in SSA countries with low electrification rates, particularly in Central Africa, as those markets are likely to see a scale up of off-grid solutions to increase energy access. To understand the full extent of SHS market expansion, a database should also be created, which keeps track of the percentage of the population utilising SHSs.

Most policy recommendations from the reviewed papers focussed on improving affordability and accessibility of good quality SHSs for households. This could be achieved by developing a stronger regulatory framework for SHSs and embedding the different solar technologies within the government's electrification strategy. National or even international quality standards for both SHSs and appliances should be established and enforced by governments to reduce low quality solar products with subsidy schemes linked to meeting requisite quality standards. Governments should raise the number of financing schemes, promote enabling taxes and impose VAT and import duty exemptions on SHS equipment, as this could reduce prices for companies and support scale-up of SHS solutions.

It is important to remember that every country is different and not all these measures will be relevant or possible in each of them. Particularly, as many SSA countries are under financial strain and need to contend with healthcare, education and infrastructure developments. Therefore, placing the responsibility to solve the country's energy access challenges solely on the government may not be the most viable strategy. Global organisations have a role to play in providing seed funding for innovative projects. However, partnerships with private sector companies are crucial to improve access and foster local capacity building, especially as these companies have a strong footprint in the off-grid market. Innovative PAYG models are becoming more prevalent and if accompanied by robust long-term maintenance solutions, they can support sustained energy access. Our study offers recommendations to support pathways for transitioning to clean energy solutions, specifically SHSs, in SSA countries. 


\section{$\underline{\text { Acknowledgement }}$}

We would like to thanks BBOXX and UCL for funding the doctoral research of the lead author. We would also like to thank the Engineering and Physical Sciences Research Council for the award of the research grant [1926633]. The second author would like to acknowledge funding from the Royal Academy of Engineering, BBOXX and UCL for her fellowship titled Smart Solar Solutions for All. We would also like to thank Margarita Royo for reviewing our work.

\section{$\underline{\text { References }}$}

Abdul-Salam, Y., \& Phimister, E. (2019). Modelling the impact of market imperfections on farm household investment in stand-alone solar PV systems. World Development, 116, 6676. https://doi.org/10.1016/j.worlddev.2018.12.007

Adwek, G., Boxiong, S., Ndolo, P. O., Siagi, Z. O., Chepsaigutt, C., Kemunto, C. M., ... Yabo, A. C. (2019). The solar energy access in Kenya: a review focusing on Pay-As-You-Go solar home system. Environment, Development and Sustainability. Springer Netherlands. https://doi.org/10.1007/s10668-019-00372-X

Azimoh, C. L., Klintenberg, P., Wallin, F., \& Karlsson, B. (2015a). Illuminated but not electrified: An assessment of the impact of Solar Home System on rural households in South Africa. Applied Energy, 155, 354-364. https://doi.org/10.1016/j.apenergy.2015.05.120

Azimoh, C. L., Klintenberg, P., Wallin, F., \& Karlsson, B. (2015b). The Burden of Shading and Location on the Sustainability of South African Solar Home System Program. Energy Procedia, 75, 308-313. https://doi.org/10.1016/j.egypro.2015.07.360

Azimoh, C. L., Klintenberg, P., Wallin, F., Karlsson, B., \& Mbohwa, C. (2016). Electricity for development: Mini-grid solution for rural electrification in South Africa. Energy Conversion and Management, 110, 268-277. https://doi.org/10.1016/j.enconman.2015.12.015

Azimoh, C. L., Wallin, F., Klintenberg, P., \& Karlsson, B. (2014). An assessment of unforeseen losses resulting from inappropriate use of solar home systems in South Africa. Applied Energy, 136, 336-346. https://doi.org/10.1016/j.apenergy.2014.09.044

Barrie, J., \& Cruickshank, H. J. (2017). Shedding light on the last mile: A study on the diffusion of Pay As You Go Solar Home Systems in Central East Africa. Energy Policy, 107, 425-436. Retrieved from https://ac.els-cdn.com/S0301421517303002/1-s2.0S0301421517303002-main.pdf?_tid=03d08a8c-ae73-11e7-b6a900000aacb360\&acdnat=1507719647_70f4b8b15e991cbe0ce066b698e7a8f7

Bensch, G., Grimm, M., Huppertz, M., Langbein, J., \& Peters, J. (2018). Are promotion programs needed to establish off-grid solar energy markets? Evidence from rural Burkina Faso. Renewable and Sustainable Energy Reviews, 90(December 2017), 1060-1068. https://doi.org/10.1016/j.rser.2017.11.003

Bisaga, I., \& Parikh, P. (2018). To climb or not to climb? Investigating energy use behaviour among Solar Home System adopters through energy ladder and social practice lens. Energy Research and Social Science, 44(May), 293-303. https://doi.org/10.1016/j.erss.2018.05.019

Bisaga, I., Parikh, P., Mulugetta, Y., \& Hailu, Y. (2018). The potential of performance targets (imihigo) as drivers of energy planning and extending access to off-grid energy in rural Rwanda. Wiley Interdisciplinary Reviews: Energy and Environment, 8(1), 1-14. https://doi.org/10.1002/wene.310

Bisaga, I., Puźniak-Holford, N., Grealish, A., Baker-Brian, C., \& Parikh, P. (2017). Scalable off-grid energy services enabled by IoT: A case study of BBOXX SMART Solar. Energy 
Policy, 109, 199-207. https://doi.org/10.1016/J.ENPOL.2017.07.004

Brown, E., Leary, J., Davies, G., Batchelor, S., \& Scott, N. (2017). eCook: What behavioural challenges await this potentially transformative concept? Sustainable Energy Technologies and Assessments, 22(2017), 106-115. https://doi.org/10.1016/j.seta.2017.02.021

Brunet, C., Savadogo, O., Baptiste, P., \& Bouchard, M. A. (2018). Shedding some light on photovoltaic solar energy in Africa - A literature review. Renewable and Sustainable Energy Reviews, 96(August), 325-342. https://doi.org/10.1016/j.rser.2018.08.004

Campana, P. E., Holmberg, A., Pettersson, O., Klintenberg, P., Hangula, A., Araoz, F. B., ... Yan, J. (2016). An open-source optimization tool for solar home systems: A case study in Namibia. Energy Conversion and Management, 130, 106-118. https://doi.org/10.1016/j.enconman.2016.10.003

Chattopadhyay, D., Bazilian, M., \& Lilienthal, P. (2015). More Power, Less Cost: Transitioning Up the Solar Energy Ladder from Home Systems to Mini-Grids. The Electricity Journal, 28(3), 41-50. https://doi.org/10.1016/j.tej.2015.03.009

Conway, D., Robinson, B., Mudimu, P., Chitekwe, T., Koranteng, K., \& Swilling, M. (2019). Exploring hybrid models for universal access to basic solar energy services in informal settlements: Case studies from South Africa and Zimbabwe. Energy Research and Social Science, 56(July 2018), 101202. https://doi.org/10.1016/j.erss.2019.05.012

Cross, J., \& Murray, D. (2018). The afterlives of solar power: Waste and repair off the grid in Kenya. Energy Research and Social Science, 44(April), 100-109. https://doi.org/10.1016/j.erss.2018.04.034

Diallo, A., \& Moussa, R. K. (2019). The effects of solar home system on welfare in off-grid areas: Evidence from Côte d'Ivoire. Energy, 194, 116835. https://doi.org/10.1016/j.energy.2019.116835

Diouf, B., \& Avis, C. (2019). The potential of Li-ion batteries in ECOWAS solar home systems. Journal of Energy Storage, 22(January), 295-301. https://doi.org/10.1016/j.est.2019.02.021

Diouf, B., \& Pode, R. (2013). Development of solar home systems for home lighting for the base of the pyramid population. Sustainable Energy Technologies and Assessments, 3, $27-$ 32. https://doi.org/10.1016/j.seta.2013.05.005

Dugoua, E., \& Urpelainen, J. (2014). Relative deprivation and energy poverty: when does unequal access to electricity cause dissatisfaction? International Journal of Energy Research, 38, 1727-1740. https://doi.org/10.1002/er.3200

Duke, R. D., Jacobson, A., \& Kammen, D. M. (2002). Photovoltaic module quality in the Kenyan solar home systems market. Energy Policy, 30(6), 477-499. https://doi.org/10.1016/S0301-4215(01)00108-2

Ellegård, A., Arvidson, A., Nordström, M., Kalumiana, O. S., \& Mwanza, C. (2004). Rural people pay for solar: experiences from the Zambia PV-ESCO project. Renewable Energy, 29(8), 1251-1263. https://doi.org/10.1016/j.renene.2003.11.019

Feron, S. (2016). Sustainability of Off-Grid Photovoltaic Systems for Rural Electrification in Developing Countries: A Review. Sustainability. https://doi.org/10.3390/su8121326

Friebe, C. A., Flotow, P. von, \& Täube, F. A. (2013a). Exploring the link between products and services in low-income markets-Evidence from solar home systems. Energy Policy, 52, 760-769. https://doi.org/10.1016/j.enpol.2012.10.038

Friebe, C. A., Flotow, P. von, \& Täube, F. A. (2013b). Exploring the link between products and services in low-income markets-Evidence from solar home systems. Energy Policy, 52, 760-769. https://doi.org/10.1016/J.ENPOL.2012.10.038

Glemarec, Y. (2012). Financing off-grid sustainable energy access for the poor. Energy Policy, 47(SUPPL.1), 87-93. https://doi.org/10.1016/j.enpol.2012.03.032

GOGLA. (2018). Off-Grid Solar Market Trends Report 2018. Washington DC. Retrieved from http://sun-connectnews.org/fileadmin/DATEIEN/Dateien/New/2018_Off_Grid_Solar_Market_Trends_Repo 
rt_Full.pdf

GOGLA. (2019). Global Off-Grid Solar Market Report Semi-Annual Sales and Impact Data. Utrecht, Netherlands. Retrieved from

https://www.gogla.org/sites/default/files/resource_docs/global_offgrid_solar_market_report_h1_2019.pdf

Green, J. M., \& Erskine, S. H. (1999). Solar (photovoltaic) systems, energy use and business activities in Maphephethe, KwaZulu-Natal. Development Southern Africa, 16(2), 221-237. https://doi.org/10.1080/03768359908440074

Green, J. M., Wilson, M., \& Cawood, W. (2001). Maphephethe rural electrification (photovoltaic) programme: The constraints on the adoption of solar home systems. Development Southern Africa, 18(1), 19-30. https://doi.org/10.1080/03768350123295

Green, J. M., \& Zwebe, D. I. (2006). From Solar Home Systems to grid electricity in lowincome rural households. Journal of Energy in Southern Africa, 17(2), 10-16.

Gustavsson, M. (2007a). Educational benefits from solar technology-Access to solar electric services and changes in children's study routines, experiences from eastern province Zambia. Energy Policy, 35(2), 1292-1299. https://doi.org/10.1016/j.enpol.2006.03.019

Gustavsson, M. (2007b). With time comes increased loads-An analysis of solar home system use in Lundazi, Zambia. Renewable Energy, 32(5), 796-813. https://doi.org/10.1016/J.RENENE.2006.03.015

Gustavsson, M., \& Ellegård, A. (2004). The impact of solar home systems on rural livelihoods. Experiences from the Nyimba Energy Service Company in Zambia. Renewable Energy, 29(7), 1059-1072. https://doi.org/10.1016/j.renene.2003.11.011

Gustavsson, M., \& Mtonga, D. (2005). Lead-acid battery capacity in solar home systems - Field tests and experiences in Lundazi, Zambia. Solar Energy, 79(5), 551-558. https://doi.org/10.1016/j.solener.2004.10.010

Hajat, A., Banks, D., Aiken, R., \& Shackleton, C. M. (2009). Efficacy of solar power units for small-scale businesses in a remote rural area, South Africa. Renewable Energy, 34(12), 2722-2727. https://doi.org/10.1016/j.renene.2009.05.027

Hakiri, J., Moyo, A., \& Prasad, G. (2016). Assessing the role of solar home systems in poverty alleviation: Case study of Rukungiri district in Western Uganda (November, 2015). Proceedings of the 24th Conference on the Domestic Use of Energy, DUE 2016, 1-9. https://doi.org/10.1109/DUE.2016.7466707

Hansen, U. E., Pedersen, M. B., \& Nygaard, I. (2015). Review of solar PV policies, interventions and diffusion in East Africa. Renewable and Sustainable Energy Reviews, 46, 236-248. https://doi.org/10.1016/j.rser.2015.02.046

Hirmer, S., \& Guthrie, P. (2017). The benefits of energy appliances in the off-grid energy sector based on seven off-grid initiatives in rural Uganda. Renewable and Sustainable Energy Reviews, 79(May), 924-934. https://doi.org/10.1016/j.rser.2017.05.152

IEA. (2017). Energy Access Outlook 2017: From poverty to prosperity. International Energy Agency. https://doi.org/10.1787/9789264285569-en

IEA. (2018). World Energy Outlook 2018: Electricity Access in Africa. International Energy Agency. Retrieved from http://www.iea.org/energyaccess/ \%0D\%0A

IEA. (2019a). Africa Energy Outlook 2019. France.

IEA. (2019b). International Energy Agency Electricity Access Database. International Energy Agency.

IEA. (2019c). World Energy Outlook 2019. Retrieved April 3, 2020, from https://www.iea.org/reports/world-energy-outlook-2019

Jacobson, A. (2007). Connective Power: Solar Electrification and Social Change in Kenya. World Development, 35(1), 144-162. https://doi.org/10.1016/j.worlddev.2006.10.001

Katikiro, R. E. (2016). Prospects for the Uptake of Renewable Energy Technologies in Rural Tanzania. Energy Procedia, 93(March), 229-233.

https://doi.org/10.1016/j.egypro.2016.07.175 
Kebede, K. Y., \& Mitsufuji, T. (2017). Technological innovation system building for diffusion of renewable energy technology: A case of solar PV systems in Ethiopia. Technological Forecasting and Social Change, 114, 242-253. https://doi.org/10.1016/j.techfore.2016.08.018

Kebede, K. Y., Mitsufuji, T., \& Choi, E. K. (2014a). After-sales service and local presence: Key factors for solar energy innovations diffusion in developing countries. PICMET 2014 - Portland International Center for Management of Engineering and Technology, Proceedings: Infrastructure and Service Integration, 3124-3130. https://doi.org/10.1080/14783363.2014.904566

Kebede, K. Y., Mitsufuji, T., \& Choi, E. K. (2014b). Looking for innovation system builders: A case of Solar Energy Foundation in Ethiopia. African Journal of Science, Technology, Innovation and Development, 6(4), 289-300. https://doi.org/10.1080/20421338.2014.947198

Kebede, K. Y., Mitsufuji, T., \& Islam, M. T. (2015). Building Innovation System for the Diffusion of Renewable EnergyTechnology: Practices in Ethiopia and Bangladesh. Procedia Environmental Sciences, 28(SustaiN 2014), 11-20. https://doi.org/10.1016/j.proenv.2015.07.003

Kebir, N., \& Philipp, D. (2016). The PSS quality framework for solar home systems. Energy Procedia, 93(March), 168-173. https://doi.org/10.1016/j.egypro.2016.07.166

Kennedy, R., Numminen, S., Sutherland, J., \& Urpelainen, J. (2019). Multilevel customer segmentation for off-grid solar in developing countries: Evidence from solar home systems in Rwanda and Kenya. Energy, 186, 115728. https://doi.org/10.1016/j.energy.2019.07.058

Ketlogetswe, C., \& Mothudi, T. H. (2009). Solar home systems in Botswana-Opportunities and constraints. Renewable and Sustainable Energy Reviews, 13(6-7), 1675-1678. https://doi.org/10.1016/j.rser.2008.08.007

Kovic, M. (2010). Investigating technology transfer projects and institutional development in developing countries. Management of Environmental Quality: An International Journal, 21(6), 761-772.

Kulworawanichpong, T., \& Mwambeleko, J. J. (2015). Design and costing of a stand-alone solar photovoltaic system for a Tanzanian rural household. Sustainable Energy Technologies and Assessments, 12, 53-59. https://doi.org/10.1016/j.seta.2015.10.001

Lay, J., Ondraczek, J., \& Stoever, J. (2013). Renewables in the energy transition: Evidence on solar home systems and lighting fuel choice in Kenya. Energy Economics, 40, 350-359. https://doi.org/10.1016/j.eneco.2013.07.024

Lee, J. T., \& Callaway, D. S. (2018). The cost of reliability in decentralized solar power systems in sub-Saharan Africa. Nature Energy, 3(11), 960-968. https://doi.org/10.1038/s41560-018-0240-y

Lemaire, X. (2009). Fee-for-service companies for rural electrification with photovoltaic systems: The case of Zambia. Energy for Sustainable Development, 13(1), 18-23. https://doi.org/10.1016/j.esd.2009.01.001

Lemaire, X. (2011). Off-grid electrification with solar home systems: The experience of a feefor-service concession in South Africa. Energy for Sustainable Development, 15(3), 277283. https://doi.org/10.1016/j.esd.2011.07.005

Lemaire, X. (2018). Solar home systems and solar lanterns in rural areas of the Global South: What impact? Wiley Interdisciplinary Reviews: Energy and Environment, 7(5), 1-22. https://doi.org/10.1002/wene.301

Levin, T., \& Thomas, V. M. (2016). Can developing countries leapfrog the centralized electrification paradigm? Energy for Sustainable Development, 31, 97-107. https://doi.org/10.1016/j.esd.2015.12.005

Lighting Global, \& World Bank Group. (2020). Off-Grid Solar Market Trends Report 2020. Washington. https://doi.org/10.1017/CBO9781107415324.004

Mapako, M. (2005). Provision of long-term maintenance support for solar photovoltaic systems 
- Lessons from a Zimbabwean NGO. Journal of Energy in Southern Africa, 16(4), 21-26.

Martinot, E., Cabraal, A., \& Mathur, S. (2001). World Bank/GEF solar home system projects: experiences and lessons learned 1993-20001Eric Martinot conducted the work herein as an Associate of the Stockholm Environment Institute, Boston. He currently works for the Global Environment Facility. Anil Cabra. Renewable and Sustainable Energy Reviews, 5, 39-57. https://doi.org/10.1016/s1364-0321(00)00007-1

Moner-Girona, M., Ghanadan, R., Jacobson, A., \& Kammen, D. M. (2006). Decreasing PV costs in Africa: Opportunities for Rural Electrification using Solar PV in Sub-Saharan Africa. Refocus, 7(1), 40-42. https://doi.org/10.1016/S1471-0846(06)70517-0

Monyei, C. G., Adewumi, A. O., \& Jenkins, K. E. H. (2018). Energy (in)justice in off-grid rural electrification policy: South Africa in focus. Energy Research and Social Science, 44(May), 152-171. https://doi.org/10.1016/j.erss.2018.05.002

Narayan, N., Papakosta, T., Vega-Garita, V., Popovic-Gerber, J., Bauer, P., \& Zeman, M. (2017). A simple methodology for estimating battery lifetimes in Solar Home System design. 2017 IEEE AFRICON: Science, Technology and Innovation for Africa, AFRICON 2017, 1195-1201. https://doi.org/10.1109/AFRCON.2017.8095652

Narayan, N., Vega-Garita, V., Qin, Z., Popovic-Gerber, J., Bauer, P., \& Zeman, M. (2018). A modeling methodology to evaluate the impact of temperature on Solar Home Systems for rural electrification. 2018 IEEE International Energy Conference, ENERGYCON 2018, 16. https://doi.org/10.1109/ENERGYCON.2018.8398756

Nerini, F. F., Tomei, J., To, L. S., Bisaga, I., Parikh, P., Black, M., ... Mulugetta, Y. (2018). Mapping synergies and trade-offs between energy and the Sustainable Development Goals. Nature Energy, 3(1), 10-15. https://doi.org/10.1038/s41560-017-0036-5

Ngetha, H., Sasaki, M., Taheri, M., \& Mathenge, S. (2015). Energy Transitions for the Rural Community in Kenya's Central Highlands: Small Scale Solar Powered Systems. Energy Procedia (Vol. 79). Elsevier B.V. https://doi.org/10.1016/j.egypro.2015.11.458

Nieuwenhout, F. D. J., Van Dijk, A., Lasschuit, P. E., Van Roekel, G., Van Dijk, V. A. P., Hirsch, D., ... Wade, H. (2001). Experience with solar home systems in developing countries: A review. Progress in Photovoltaics: Research and Applications, 9(6), 455474. https://doi.org/10.1002/pip.392

Nygaard, I., Hansen, U. E., Mackenzie, G., \& Pedersen, M. B. (2017). Measures for diffusion of solar PV in selected African countries. International Journal of Sustainable Energy, 36(7), 707-721. https://doi.org/10.1080/14786451.2015.1086768

Okou, R., Mwaba, G., Khan, M. A., Barendse, P., \& Pillay, P. (2009). High speed electromechanical flywheel design for rural electrification in sub saharan africa. 2009 IEEE International Electric Machines and Drives Conference, IEMDC '09, 392-398. https://doi.org/10.1109/IEMDC.2009.5075236

Okou, R., Sebitosi, A. B., \& Pillay, P. (2011). Flywheel rotor manufacture for rural energy storage in sub-Saharan Africa. Energy, 36(10), 6138-6145. https://doi.org/10.1016/j.energy.2011.07.051

Ondraczek, J. (2013). The sun rises in the east (of Africa): A comparison of the development and status of solar energy markets in Kenya and Tanzania. Energy Policy, 56, 407-417. https://doi.org/10.1016/j.enpol.2013.01.007

Opiyo, N. (2016). A survey informed PV-based cost-effective electrification options for rural sub-Saharan Africa. Energy Policy, 91, 1-11. https://doi.org/10.1016/j.enpol.2015.12.044

Opiyo, N. (2019). Impacts of neighbourhood influence on social acceptance of small solar home systems in rural western Kenya. Energy Research and Social Science, 52(January), 91-98. https://doi.org/10.1016/j.erss.2019.01.013

Pailman, W. L., Kruger, W., \& Prasad, G. (2015). Mobile payment innovation for sustainable energy access. Proceedings of the 23rd Conference on the Domestic Use of Energy, DUE 2015, 39-44. https://doi.org/10.1109/DUE.2015.7102961

Park, W. Y., \& Phadke, A. A. (2017). Adoption of energy-efficient televisions for expanded 
off-grid electricity service. Development Engineering, 2(July), 107-113.

https://doi.org/10.1016/j.deveng.2017.07.002

Pode, R. (2013). Financing LED solar home systems in developing countries. Renewable and Sustainable Energy Reviews, 25, 596-629. https://doi.org/10.1016/j.rser.2013.04.004

Posorski, R., Bussmann, M., \& Menke, C. (2003). Does the use of solar home systems (SHS) contribute to climate protection? Renewable Energy, 28(7), 1061-1080. https://doi.org/10.1016/S0960-1481(02)00056-3

Practical Action. (2014). Poor People's Energy Outlook 2014. Rugby. Retrieved from http://infohub.practicalaction.org/oknowledge/bitstream/11283/556929/9/PPEO_English_ 2014_LowRes_New.pdf

Quansah, D. A., Adaramola, M. S., \& Mensah, L. D. (2016). Solar Photovoltaics in subSaharan Africa - Addressing Barriers , Unlocking Potential. Energy Procedia, 106, 97110. https://doi.org/10.1016/j.egypro.2016.12.108

Rolffs, P., Ockwell, D., \& Byrne, R. (2015). Beyond technology and finance: pay-as-you-go sustainable energy access and theories of social change. Environment and Planning A, 47(12), 2609-2627. https://doi.org/10.1177/0308518X15615368

Schelling, N., Hasson, M. J., Huong, S. L., Nevarez, A., Lu, W.-C., Tierney, M., ... Schützeichel, H. (2010). SIMbaLink: towards a sustainable and feasible solar rural electrification system. Proceedings of the 4th ACM/IEEE International Conference on Information and Communication Technologies and Development - ICTD '10, 1-10. https://doi.org/10.1145/2369220.2369260

Schillebeeckx, S. J. D., Parikh, P., Bansal, R., \& George, G. (2012). An integrated framework for rural electrification: Adopting a user-centric approach to business model development. Energy Policy, 48, 687-697. https://doi.org/10.1016/j.enpol.2012.05.078

Scott, I. (2017). A business model for success: Enterprises serving the base of the pyramid with off-grid solar lighting. Renewable and Sustainable Energy Reviews, 70(November 2016), 50-55. https://doi.org/10.1016/j.rser.2016.11.179

Simon, M., \& Meyer, E. L. (2008). Spectral distribution on photovoltaic module performance in South Africa. Conference Record of the IEEE Photovoltaic Specialists Conference. https://doi.org/10.1109/PVSC.2008.4922590

Smith, M. G., \& Urpelainen, J. (2014). Early Adopters of Solar Panels in Developing Countries : Review of Policy Research, 31(1).

Soltowski, B., Bowes, J., Strachan, S., \& Anaya-Lara, O. L. (2018). A Simulation-Based Evaluation of the Benefits and Barriers to Interconnected Solar Home Systems in East Africa. 2018 IEEE PES/IAS PowerAfrica, PowerAfrica 2018, 1, 491-496. https://doi.org/10.1109/PowerAfrica.2018.8521058

Steel, W. F., Anyidoho, N. A., Dadzie, F. Y., \& Hosier, R. H. (2016). Developing rural markets for solar products: Lessons from Ghana. Energy for Sustainable Development, 31, 178184. https://doi.org/10.1016/j.esd.2016.02.003

Stojanovski, O., Thurber, M., \& Wolak, F. (2017a). Rural energy access through solar home systems : Use patterns and opportunities for improvement. Energy for Sustainable Development, 37, 33-50. https://doi.org/10.1016/j.esd.2016.11.003

Stojanovski, O., Thurber, M., \& Wolak, F. (2017b). Rural energy access through solar home systems: Use patterns and opportunities for improvement. Energy for Sustainable Development, 37, 33-50. https://doi.org/10.1016/j.esd.2016.11.003

Taele, B. M., Mokhutšoane, L., Hapazari, I., Tlali, S. B., \& Senatla, M. (2012). Grid electrification challenges, photovoltaic electrification progress and energy sustainability in Lesotho. Renewable and Sustainable Energy Reviews, 16(1), 973-980. https://doi.org/10.1016/j.rser.2011.09.019

Tillmans, A., \& Schweizer-Ries, P. (2011). Knowledge communication regarding solar home systems in Uganda: The consumers' perspective. Energy for Sustainable Development, 15(3), 337-346. https://doi.org/10.1016/j.esd.2011.07.003 
Ubisse, A., \& Sebitosi, A. (2009). A new topology to mitigate the effect of shading for small photovoltaic installations in rural sub-Saharan Africa. Energy Conversion and Management, 50(7), 1797-1801. https://doi.org/10.1016/j.enconman.2009.03.016

Uddin, K., Prinsloo, G., Marco, J., \& Jennings, P. (2017). Techno-Economic Analysis of the Viability of Solar Home Systems Using Lithium-ion Batteries in Sub-Saharan Africa. Energy Procedia, 138, 267-272. https://doi.org/10.1016/j.egypro.2017.10.053

van der Plas, R. J., \& Hankins, M. (1998). Solar electricity in Africa: a reality. Energy Policy, 26(4), 295-305. https://doi.org/10.1016/S0301-4215(97)00157-2

van der Vleuten, F., Stam, N., \& van der Plas, R. (2007). Putting solar home system programmes into perspective: What lessons are relevant? Energy Policy, 35(3), 14391451. https://doi.org/10.1016/j.enpol.2006.04.001

Wamukonya, N., \& Davis, M. (2001). Socio-economic impacts of rural electrification in Namibia: comparisons between grid, solar and unelectrified households. Energy for Sustainable Development, 5(3), 5-13. https://doi.org/10.1016/S0973-0826(08)60272-0

Zhang, F. (2014). Can solar panels leapfrog power grids? the World Bank experience 19922009. Renewable and Sustainable Energy Reviews, 38, 811-820. https://doi.org/10.1016/j.rser.2014.07.047

Zubi, G., Dufo-López, R., Pardo, N., \& Pasaoglu, G. (2016). Concept development and technoeconomic assessment for a solar home system using lithium-ion battery for developing regions to provide electricity for lighting and electronic devices. Energy Conversion and Management, 122, 439-448. https://doi.org/10.1016/j.enconman.2016.05.075

Zubi, G., Spertino, F., Carvalho, M., Adhikari, R. S., \& Khatib, T. (2017). Development and assessment of a solar home system to cover cooking and lighting needs in developing regions as a better alternative for existing practices. Solar Energy, 155, 7-17. https://doi.org/10.1016/j.solener.2017.05.077 